\title{
Auditory-Visual Matching and Language-Based Learning Disorders: Two Studies of Specific Language Impairment and Developmental Dyslexia
}

\author{
Minna R. K. Törmänen \\ University of Helsinki \\ Department of Applied Sciences of Education, Special Education \\ P.O. Box 26 (Teollisuuskatu 23), FIN-00014 University of Helsinki, Finland
}

Tel.: 358-40-7406063Ｅmail: minna.tormanen@helsinki.fi

\begin{abstract}
This is a binary study about auditory-visual matching in language-based learning disorders $(\mathrm{N}=212)$. Much controversy ensures about the extent to which auditory processing deficits are important in the genesis of language-based learning disorders, particularly specific language impairment and developmental dyslexia. Explorative study 1 focused on children between the ages of 6 and 13, with SLI $(\mathrm{N}=84)$, dyslexia $(\mathrm{N}=52)$ and typical language development $(\mathrm{N}=28)$. The results showed that children with SLI experience very similar difficulties to those of children with dyslexia in auditory-visual matching. Comorbidity was evident, as $63 \%$ of children had additional diagnoses. Encouraged by interesting results, an intervention study was conducted. Study 2 involved 48 children, [pre-schoolers $(\mathrm{N}=23)$, first-graders $(\mathrm{N}=25)]$ who participated in the auditory-visual matching training period. After the training, an improvement in the auditory-visual matching test was found. The positive effect was also evident based on the Assessment Inventories, which evaluate the development of overall cognitive performances.
\end{abstract}

Keywords: Auditory-visual Matching, Language-based learning disabilities, Specific language impairment, Developmental dyslexia, Comorbidity, Computer program, Intervention 


\section{Introduction}

Language may be viewed as a necessary tool for successful academic, social, and behavioral achievement. This notion would predict that young children with poor language skills would be at risk for later learning and social problems. It is also reasonable to propose that academic, social, and behavioral experiences influence language skills.

The failure of some children to master language at a normal rate, despite normal intelligence and adequate instruction, has puzzled researchers for decades (Tallal \& Piercy, 1973; Bishop, 1992; Tallal, Miller, \& Fitch, 1993; Snowling, 1998). There is a long history and much controversy about the extent to which auditory processing deficits are important factors in the genesis of a variety of language-based learning disorders. One theoretical account proposes that auditory perceptual problems cause specific language impairment (SLI) in children (Tallal, 2000; Tallal \& Piercy 1973). Most children with SLI have literacy problems, and the theory has also been extended to account for developmental dyslexia.

This paper discusses the role of auditory-visual matching in language-based learning disorders, such as specific language impairment (SLI) and developmental dyslexia. Apart from the fact that both of these disorders involve deficits in some part of the language system, they also represent specific deficits occurring in the context of other cognitive abilities that are more or less normal. Also possible comorbidity is discussed.

\subsection{Specific Language Impairment (SLI)}

Specific language impairment, also known as developmental a- or dys-phasia, is regarded as a neurobiological disorder that seriously influences on a child's educational and psychosocial outcome. Children with SLI often being spontaneous speech late and lag behind normally developing children in acquiring sophisticated language and grammar despite having adequate hearing, at least average nonverbal intelligence, no known hearing, physical, or emotional problems, and an adequate learning environment (Asikainen, 2005; Bishop, 1992, Bishop et al., 2006; Tomblin et al., 1997). Children with SLI have deficits in receptive and expressive language, and often poor phonology and semantic skills; short-term memory problems may also occur. Because of this broad span of both language and literacy deficits, some theorists have considered SLI a more extreme form of other language disorders than dyslexia, where oral language abilities remain intact (Bishop \& Snowling, 2004). Some have proposed that SLI may result from cognitive and linguistic difficulties (van der Lely \& Stollwerck, 1997). Other theorists, however, have hypothesized that the primary deficit in SLI is in auditory processing (Tallal, 2000; Tallal \& Piercy, 1973). This is not a hearing loss in the same way as deafness is, but rather an inability to perceive, categorize, and process sounds properly, which may lead to higher-level problems. Such a perceptual processing view emphasizes the importance of the detection and discrimination of low-level, basic acoustic components, suggesting that these bottom-up problems interfere with higher linguistic processing.

Findings in SLI studies are contradictory, however, and the core problem of the disorder is still under debate. Thus far, differential diagnostics between SLI and other disorders in the 
spectrum of developmental disorders, socio-emotional disorders and learning difficulties also remain undetermined (Bishop \& Snowling, 2004; Asikainen, 2005).

\subsection{Dyslexia}

A commonly accepted definition of dyslexia is that it is a specific learning difficulty primarily affecting the acquisition of reading and spelling such that these skills remain below the level expected of a given age and general cognitive ability.

When learning to read, we develop an explicit understanding that words can be broken down into constituent phonemes, which map to visually presented letter strings, known as graphemes. Phonological-deficit theories of dyslexia, which have dominated the field for several years, view dyslexia as a cognitive difficulty in processing phonemes (Snowling 2001). Indeed, robust evidence suggests that the phonological skills of individuals with dyslexia are compromised, but this does not fit with the complexity of the phenotype, which includes an array of subtle sensory impairments and motor difficulties (Ramus, 2003).

Rapid-processing hypotheses propose that dyslexia arises from a basic deficit in rapidly processing successive and transient stimuli that enter the nervous system, thus affecting all modalities (Hari \& Renvall, 2001; Eden, Stein, Wood \& Wood, 1995). In such models, the phonological impairments responsible for reading difficulties stem from a lower-level inability to discriminate acoustic cues involved in distinguishing phonemes (Temple et al., 2000). The magnocellular deficit theory is based on data from anatomical, psychophysical, and imaging studies indicating that many people with dyslexia have mild anomalies in the magnocellular visual subsystem (Eden, 1996). Magnocells are neurons concerned with motion perception and temporal resolution, and are important for the control of eye movements. Magnocellular pathways may exist in other sensory modalities, so a multi-modal magnocell deficit could account for the full range of symptoms associated with dyslexia, with reading difficulties resulting from a combination of visual and phonological impairment (Stein \& Walsh, 1997). More recently, researchers have suggested that dyslexia represents a general impairment in skill automatization resulting from cerebellar dysfunction (Nicolson, Fawcett, \& Dean, 2001).

\subsection{Language-Based Learning Disorders and Auditory Processing}

Much controversy ensures about the extent to which auditory processing deficits are important in the genesis of language-based learning disorders, particularly in specific language impairment (Rosen, 2003). A review of the literature reveals that, on average some, but not all, auditory skills are impaired in groups of SLI listeners (Rosen, 2003). A matter of controversy is whether difficulties in segmenting, discriminating, and identifying speech sounds have their basis in a more fundamental auditory perceptual deficit affecting the processing of all sounds, not just speech (Bishop et al., 1999b).

Many children with SLI experience auditory processing difficulties, but for most children, these are not specific to brief, rapidly successive acoustic cues. Rather, sensitivity to durational and amplitude envelope cues appears to predict language and literacy outcomes more strongly. The potential role of auditory processing difficulties in explaining SLI has 
been explored in depth by Tallal and colleagues (Benasich \& Tallal, 2002; Spitz, Tallal, Flax \& Benasich, 1997; Tallal \& Piercy, 1973, 1974, 1975). They have proposed a rapid temporal processing deficit account of SLI. Difficulties in rapid temporal processing are thought to explain language problems "as speech occurs at roughly $80 \mathrm{~ms}$ per phoneme” (Tallal \& Piercy, 1973a, p. 397).

Although some studies of children with SLI have subsequently reported difficulties in rapid auditory processing (Alexander \& Frost, 1982), they have found no such difficulties in others (Bishop, Carlyon, Deeks \& Bishop, 1999; Norrelgen, Lacerda \& Forssberg, 2002). Some argue that although children with SLI may show auditory processing deficits, the rapidity of the stimuli do not characterized these deficits (see McArthur \& Bishop, 2001; Rosen, 2003). Others have argued that when children with SLI show difficulties in perceptual tasks, these difficulties may arise from auditory immaturity (Bishop, Adams, Nation \& Rosen, 2005) or from task artifacts (Coady, Kluender \& Evans, 2005). The role of auditory perceptual deficits in explaining the etiology of SLI is thus strongly debated.

Dyslexia, in this view, arises from deficits in phonological processing, which is to say a process specific to speech sounds (Snowling, 1998). Similarly, some claim SLI results from deficits in neural systems that process grammar and, more specifically, syntax (van der Lely et al., 1998). On the other hand, others have claimed that deficits in underlying nonlinguistic sensory mechanisms are the core deficit in these disorders (Ramus, 2003). Still others have made far stronger claims about the role of impaired auditory processing in the genesis of SLI and dyslexia, especially with regard to the perception of rapidly changing or transient sounds (e.g. Hari \& Renvall, 2001).

\subsection{Auditory-Visual Matching and Interventions}

The concept of auditory structuring ability (Karma, 1984, 1989, 1999, 2002b) is defined as a sub-skill of auditory processing and represents a general ability to relate tones with each other. This ability is considered clearly distinct from sensory acuity (i.e., the ability to hear small differences in the different parameters of sounds). Auditory structuring ability is very similar to spatial ability in that both consist of perceiving patterns or relationships; the role of single elements is simply to form these structures through certain relationships to each other. The difference between auditory structuring and spatial ability is that in the former, the relationships are mainly temporal and auditory, whereas in the latter, they are mainly static and visual (Karma, 1989, 1999, 2002b). Auditory structuring is represented in the segmentation and synthesis of the heard word (e.g. $C A R$; it consists of letters /k/, /a:/, and /r/ but in a specific order. Without auditory structuring it could be e.g. ACR or CRA.) Although reading is also a visual process it could be that the concept of auditory structuring is insufficient. A more useful concept could be auditory-visual matching.

Several studies have explored auditory-visual matching in children with learning disabilities, such as developmental dyslexia or ADD (Karma, 1989, 1999; Kujala et al., 2001; Törmänen \& Takala, 2009; Törmänen, Takala \& Sajaniemi, 2008) using auditory-visual matching computer training. A study by Kujala et al. (2001) aimed to determine whether audiovisual training without linguistic material has a remedial effect on reading skills and central auditory 
processing in children with dyslexia. The study found that this training resulted in plastic changes in the auditory cortex, indexed by enhanced electrophysiological mismatch negativity and faster reaction times to sound changes. Importantly, these changes were accompanied by improvements in reading skills. The results indicate not only that special training programs can improve reading difficulties but further, that brain activity can reflect the effects of training. Moreover, the fact that the effects of training were obtained by using a program that included no linguistic material indicates that dyslexia is at least partly based on a general auditory perceptual deficit (Kujala et al., 2001).

The data found in research by Corriveau et al. (2007) indicate that the auditory processing difficulties that are most strongly predictive of language and phonology in children with SLI are found in tasks requiring the integration of temporal information over relatively long temporal windows. Studies by Richardson et al. (2004) and Corriveau et al. (2007) found that the relationships among auditory processing, phonological awareness, and literacy were very similar in both samples of children with a developmental language disorder. However, the relationships appear stronger in terms of the absolute variance accounted for in the sample of children with SLI.

Could deficits in auditory processing lead to SLI in some cases and dyslexia in others? This study will focus on the empirical evidence relevant to auditory-visual matching, which posits deficiencies in auditory processing as the deficit in SLI and dyslexia. Further, children with language-based learning disorders training auditory-visual matching training underwent.

\subsection{Comorbidity}

Specific language impairment is characterized by a broad spectrum of developmental impairments (Webster et al., 2006). Approximately 7\% of children are believed to have speech and language difficulties, although this will vary with both the diagnostic criteria and the children's age (Bishop \& Adams, 1990, Tomblin et al., 1997). Because children with SLI can develop slowly in a range of domains (Haynes \& Naidoo, 1991) and experience problems with auditory, visual, tactile, phonetic, and dihaptic perception, as well as with motor tasks (Bishop \& Adams, 1990; Powell \& Bishop, 1992), researchers theorize that such problems stem from a generalized neuromaturational delay (Locke, 1994). Other proposals emphasize the role of timing in neural processing and posit that a cross-modal inability to process rapidly changing stimuli also termed pansensory (Tallal et al., 1993), may characterize developmental-language disorders (Anderson, Brown \& Tallal, 1993). This later characterization is in contrast to earlier work by Tallal and Piercy (1973a, 1974), which suggested that a modality-specific auditory-perceptual dysfunction was the underlying cause of dysphasia in children. The view implicating a pansensory deficit apparently stemmed from the failure of Tallal and colleagues to replicate modality-specific effects.

While most children's difficulties resolve, children whose difficulties persist into elementary school may have long-term problems concerning literacy, socialization, and behavior as well as school achievement. Studies have shown that students with language learning disabilities differ from their normally achieving peers not only in the development of linguistic skills, but also in the motivational and emotional profiles they display as early as in the first grade 
(Poskiparta et al., 2003). In particular, the child's ability to maintain focused attention both on the learning task and on instructional discourse benefits reading acquisition (Lepola et al., 2005; Onatsu-Arvilommi \& Nurmi, 2000; Rowe \& Rowe, 1999). One motivational component associated with teacher-student and parent-child interaction is the child's social dependence, that is, the lack of responsibility the child assumes over his or her own learning activity. The kind of other-focusing motivational tendency is especially found to be associated with surface-level cognitive processing (Graham \& Golan, 1991), as well as with learning difficulties in reading and mathematics (Vauras et al., 1999).

Language is an eminently integrative function and none of its components operate in isolation from the others. In addition, language development is functionally dependent on emotional regulation (Fujiki et al., 2002). Taking this into account, it is unsurprising that children with SLI commonly exhibit comorbidity in other developmental areas, such as psychiatric and behavioral disorders (Glogowska et al., 2006; McCabe, 2005; Westby \& Blalock, 2005; Toppelberg \& Shapiro, 2000; Beitchman et al.,1996). A study by Estrem (2005) confirmed connection between problem behavior and language development, documenting that observed aggression increased as expressive and receptive language scores decreased in 100 preschoolers. Other studies (Bruce, 2006; Beitchman et al., 2001; Cohen et al., 2000) have also revealed a significant interrelationship between language disorders, attention deficit disorders and autism spectrum disorders.

The development of language is also intertwined with the development of motor skills (Bishop, 2002). According Webster et al. (2005), children identified on the basis of language impairment show significant motor comorbidity. The common association between language and phonologic impairment identified in children with SLI (Leonard, 1998) raises the possibility that factors contributing to motor planning and sequencing may also be important in other phases of language processing. Motor deficits observed in SLI are usually described similarly to those identified in other neurodevelopment disorders such as developmental coordination disorder (Hill, 2001). The fact that various disorders overlap in SLI seems to indicate a shared underlying etiology and that behavioral expressions of disorders differ due to various factors such as the timing and severity of disruption to brain development (Gilger \& Kaplan, 2001).

\section{Purpose of the Study}

The purpose of this binary study was to investigate the role of auditory-visual matching and overall cognitive performances of children with language-based learning disorders, such as specific language impairment and developmental dyslexia.

\section{Study Design and Methods}

The study design consists of two different studies. Study 1 ( $\mathrm{N=164)}$ was explorative focusing on auditory-visual matching and overall cognitive performances of children with SLI ( $n=84)$. Results of auditory-visual matching of children with developmental dyslexia $(n=52)$ and typical language development, TLD $(n=28)$ were used as background information. 


\section{Macrothink Institute ${ }^{\mathrm{TM}}$}

Encouraged by interesting results of study 1, a study 2, an intervention study was conducted with children with language-based learning disorders, like SLI and dyslexia ( $\mathrm{N}=48)$.

\section{STUDY 1:}

\section{SLI (N=84), Dyslexia ( $\mathrm{N}=52)$, TLD $(\mathrm{N}=28)$}

1. Auditory-visual matching test $(\mathrm{N}=164)$

2. Standardized Elementary School Reading Test Battery ( $n=84$; children with SLI)

3. Assessment Inventory $(n=84$; children with SLI)

\section{STUDY 2:}

Language-Based Learning Disorders ( $\mathrm{N}=48)$

1. Auditory-visual matching test

$(\mathrm{N}=48)$

2. Standardized Elementary School Reading Test Battery $(n=25)$

3. or School-readiness Assessment $(n=2.3)$

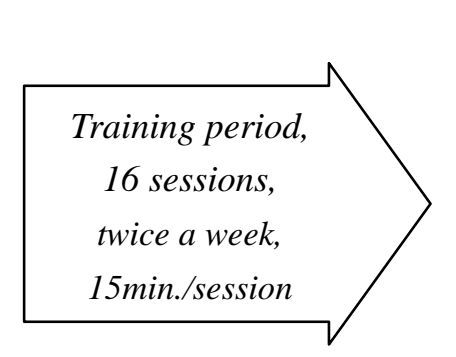

1. Auditory-visual matching test $(\mathrm{N}=48)$

2. Assessment Inventory $(\mathrm{N}=48)$

Figure 1. The Study Design

The main research method of both studies was the Auditory-Visual Matching Test, also an Assessment Inventory of overall cognitive performance and reading-skill tests (see chapters 4.2.1 and 5.2.1) were used. Study 2 involved nonverbal audio-visual computer training, called Audilex (see chapter 5.2.2). 


\section{Macrothink}

\subsection{The Auditory-Visual Matching Test}

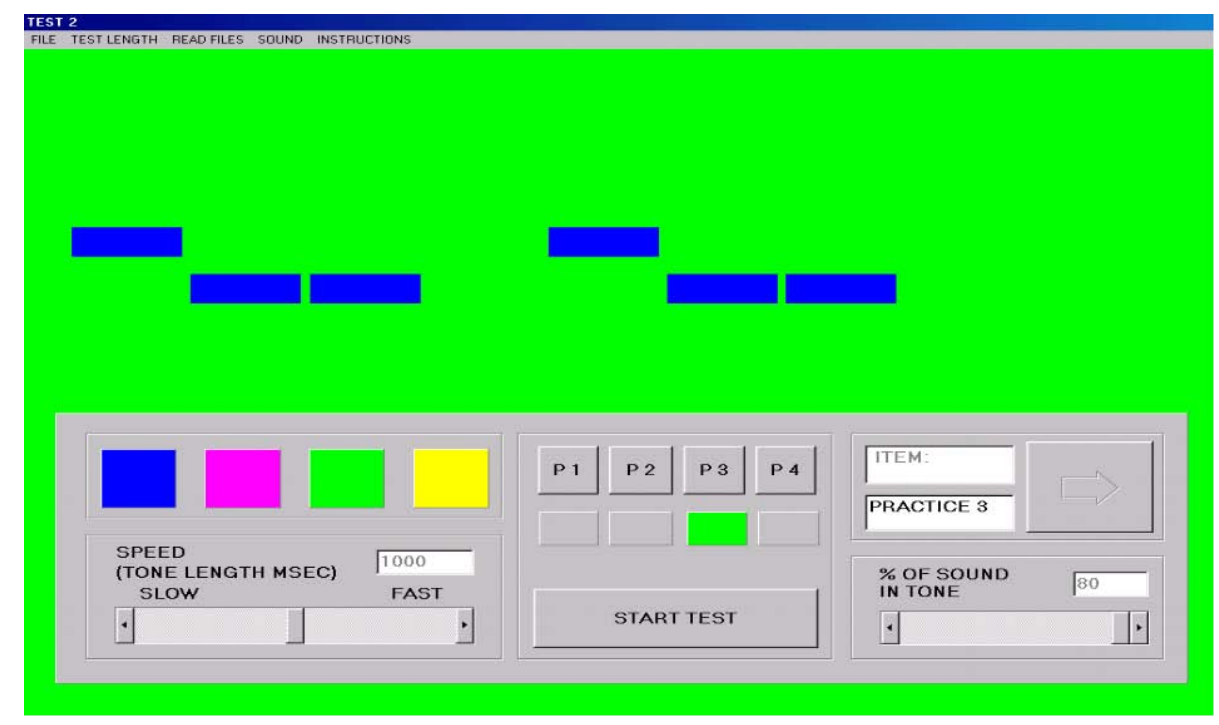

Figure 2. The Auditory-Visual Matching Test

Each child in studies 1 and 2 participated in the Auditory-Visual Matching Test (Karma, 1998). Test version 2 of the computer program devised by Karma (1998) was used (Figure 2), which consisted of abstract, nonverbal tasks requiring auditory-visual matching. The auditory-visual matching test included a set of 30 tasks. In the test, a pattern was displayed on a computer screen, after which a sound pattern was played; the pattern remained on the screen throughout the entire task. Various sound patterns featuring 3 to 15 elements were graphically represented on the screen as horizontal sequences of rectangles. The sound elements varied in pitch, duration, and intensity (see Figure 3), and were visually represented on the screen by the respective vertical position, length, and thickness of the rectangles. Participants pressed the space bar on a computer keyboard when the sound pattern matched the rectangle on the screen. The time window for doing this was when the last sound of the pattern was being played. When a participant responded correctly, the computer registered a hit. Stimulus elements were presented with a 1,000-ms stimulus (element)-onset asynchrony (SOA) and a 550-ms sound duration throughout the test, following the same regulation as those used in the studies of Karma (1999) and Kujala et al. (2001). A computer screen presented four different choices of colors: blue, purple, green, yellow. A researcher conducted the auditory-visual matching test, which included a practice session, at a school in a quiet classroom suitable for special education. 


\section{Game patterns}
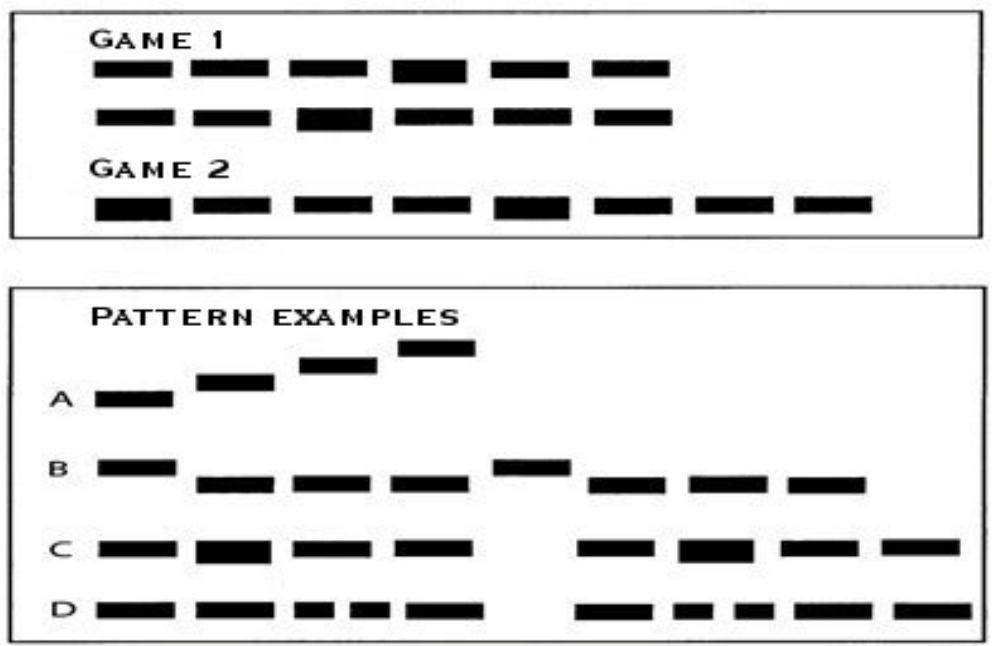

Figure 3. Task Examples of the Patterns Used in The Auditory-Visual Matching Test

\subsection{Assessment Inventory}

To explore different skills, possible deficits and comorbid problems in the overall cognitive development of children with language-based learning disorders such as SLI and developmental dyslexia, a researcher-developed Assessment Inventory was used (see Appendix). The special education teachers evaluated students. The inventory consisted of four different categories of children's development: sensory, cognitive, socio-emotional and motor. Attention focused largely on evaluating maturational aspects: 1) Auditory, visual and tactile discrimination in sensory abilities; 2) Children's use of cognitive skills and strategies, such as linguistic skills (like semantics and dysnomia), memory (like auditory memory), and logical thinking; 3) Socio-emotional skills through motivation, task orientation, social dependence, and ego-defensive orientation, as well as interaction skills and the ability to concentrate; 4) Students' somatic knowledge, fine, gross-motor and sensor-motor functions in motor development.

\section{Study 1}

\subsection{Participants in Study 1}

In study 1, 164 children ranging in age from 6 years (78 months) to 13 years (158 months) $(\mathrm{M}=110, \mathrm{SD}=20)$ were involved (Table 1). 84 children with diagnosis of SLI served as participants in all three measurements. The test results of auditory-visual matching of children with a diagnosis of dyslexia $(n=52)$, and typical language development, (TLD) $(n=28)$ served as background information. The children with typical language development were first-graders (6 to 8 yrs), because based on earlier research (Karma 2002b) and test results children with TLD had no difficulties in auditory-visual matching. 
Table 1. Number of Subjects and Average Ages in Study 1

\begin{tabular}{|c|c|c|c|c|c|c|c|}
\hline & \multicolumn{3}{|c|}{ Girls } & \multicolumn{3}{|c|}{ Boys } & \\
\hline & 6-8 yrs & 9-10 yrs & 11 -13yrs & 6-8 yrs & 9-10 yrs & 11-13yrs & $\mathbf{N}$ \\
\hline SLI & $9 \quad(93)^{*}$ & 8 (116) & $8(140)$ & $23(95)$ & $22(115)$ & $14(142)$ & 84 (114) \\
\hline Dyslexia & $4 \quad(104)$ & $6 \quad(125)$ & $1(139)$ & $19(100)$ & 16 (119) & $6(141)$ & 52 (115) \\
\hline TLD** & $18(87)$ & & & $10(84)$ & & & $28(86)$ \\
\hline $\mathbf{N}$ & 31 (91) & $14(120)$ & $9(140)$ & 52 (95) & 38 (117) & $20(142)$ & $164(110)$ \\
\hline
\end{tabular}

Note. * Age in months.

Note. ${ }^{* *}$ TLD $=$ Children with Typical Language Development

Note. Age in months varies between 78 and 158 months.

The participants with a diagnosis of SLI $(n=84)$ came from the same special elementary school in Finland. A certified speech-language clinician had previously been diagnosed these children by with SLI [(F 80 Specific developmental disorders of speech and language) ICD-10]. Children with SLI had an Individualized Education Plan (IEP) and they received speech therapy in their schools. $63 \%$ of children had additional diagnosis according to the International Statistical Classification of Diseases and Related Health Problems (see Table 2).

Table 2. Study 1: Additional diagnoses in the SLI group according to the International Statistical Classification of Diseases and Related Health Problems (N=53)

\begin{tabular}{|l|l|}
\hline SLI + one other diagnosis & $\mathbf{4 0}$ \\
\hline F81 Specific developmental disorders of scholastic skills & 18 \\
\hline F82 Specific developmental disorder of motor function & 13 \\
\hline F84.5 Asperger's syndrome & 2 \\
\hline F90 Hyperkinetic disorders & 4 \\
\hline G40 Epilepsy & 2 \\
\hline E10 Diabetes & 1 \\
\hline SLI + two other diagnoses & $\mathbf{1 3}$ \\
\hline $\begin{array}{l}\text { F81 Specific developmental disorders of scholastic skills + F90 Hyperkinetic } \\
\text { disorders }\end{array}$ & 3 \\
\hline $\begin{array}{l}\text { F81 Specific developmental disorders of scholastic skills + F82 Specific } \\
\text { developmental } \\
\text { disorder of motor function }\end{array}$ & 1 \\
\hline $\begin{array}{l}\text { F81 Specific developmental disorders of scholastic skills + F98 Other behavioral and } \\
\text { emotional disorders with onset usually occurring in childhood }\end{array}$ & 1 \\
\hline F90 Hyperkinetic disorders + F82 Specific developmental disorder of motor function & 5 \\
\hline $\begin{array}{l}\text { F90 Hyperkinetic disorders + F95.2 Combined vocal and multiple motor tic disorder } \\
\text { (Tourettés syndrome) }\end{array}$ & 1 \\
\hline F90 Hyperkinetic disorders + Premature Infant & 1 \\
\hline Paresis nervi + Expansio medulla oblongata + Mild mental retardation & 1 \\
\hline
\end{tabular}


A qualified educational psychologist or special education teacher, followed the general curriculum, had formally diagnosed the children with dyslexia $(n=52)$ whose test results of auditory-visual matching served as background information. These children were diagnosed with developmental dyslexia only (i.e. no other diagnosed disabilities). Due to their dyslexia, they had received remediation from special education teachers since the first grade (age seven), which took place once or twice a week with a special education teacher in a resource room. The participants came from three different mainstream elementary schools in the same Swedish town.

Based on school records and background information supplied by their teachers, the children with typical language development $(n=28)$ had no history of speech, language, or hearing problems or of any other exceptional educational needs and came from same elementary school from Finland.

\subsection{Methods in Study 1}

Every child in this study participated in the Auditory-Visual Matching Test (Karma, 1998). In study 1, two additional measures were used to classify the children with SLI: 1) the Reading Test for Elementary School (Lindeman, 1998) and 2) the Assessment Inventory.

4.2.1 Reading-skill tests

Two sub-tests of the Standardized Elementary School Reading Test Battery, called ALLU (Lindeman, 2000), develop to evaluate the reading status of 7 - to 13-year-old Finnish-speaking children served to assess decoding and reading comprehension through the use of test battery that included age-matched tasks.

The decoding test (max. 9) consisted of word and sentence recognition, which included, for example, letter cluster identification, picture-word matching, and picture-sentence matching, silent word decoding, and word recognition. Every task had four alternative answers. The reading comprehension test (max. 9) included a narrative story and an expository text together with questions, each of which had four alternative answers. The questions assessed literal (e.g., fact finding, information ordering) and inferential text comprehension skills (e.g., deriving word meaning and making inferences beyond the sentence level). Each correct answer earned one point. The children's speech therapists or special education teachers carried out the individual testing in two 30-45-min sessions. Each child could refer to the text for the entire duration of the test.

\subsection{Results of Study 1}

The data were analyzed using the statistical package SPSS for Windows (version 15.0, SPSS). Table 3 presents group means and standard deviations from the Auditory-Visual Matching Test. The results of the children diagnosed with SLI were below average (see Table 3.) as were those of the children diagnosed with dyslexia. Children with Typical Language Development showed no difficulties in the Auditory-Visual Matching Test Cronbach's Alpha coefficients were over .85. 
Table 3. Descriptive Information of The Auditory-Visual Matching Test (max. 30) in Study 1

\begin{tabular}{|c|c|c|}
\hline & M & (SD) \\
\hline SLI* & 23.42 & $(4.94)$ \\
\hline 6-8 yrs & 21.69 & $(5.62)$ \\
\hline 9-10 yrs & 24.47 & $(4.39)$ \\
\hline 11-13yrs & 24.55 & $(3.99)$ \\
\hline Dyslexia & 21.56 & $(6.34)$ \\
\hline 6-8 yrs & 18.00 & $(7.37)$ \\
\hline 9-10 yrs & 24.14 & $(2.98)$ \\
\hline 11-13yrs & 25.14 & $(4.85)$ \\
\hline TLD** & & \\
\hline 6-8 yrs & 28.86 & $(1.65)$ \\
\hline
\end{tabular}

Note. $*$ SLI $=$ Specific Language Impairment

Note. ${ }^{* *}$ TLD $=$ Children with Typical Language Development

The Standardized Elementary School Reading Test Battery showed that the overall reading level of children with SLI was below the age-normal range. Mean scores of word and sentence recognition and sentence comprehension appear in Table 4.

Table 4. Descriptive Information from Used Tests with Children with SLI in Study 1

\begin{tabular}{|l|l|l|l|l|l|l|l|l|l|l|}
\hline & & & $6-8$ yrs & \multicolumn{2}{c|}{$9-10$ yrs } & \multicolumn{2}{l|}{11 -13yrs } \\
\hline & M & (SD) & M & (SD) & M & (SD) & M & (SD) \\
\hline Standardized Elementary School Reading Test Battery (max. 9) \\
\hline Reading Comp.* & $3.04^{* *}$ & $(1.70)$ & 2.75 & $(1.65)$ & 3.10 & $(1.75)$ & 3.36 & $(1.71)$ \\
\hline Decoding & $2.79^{* *}$ & $(1.76)$ & 2.63 & $(1.79)$ & 2.97 & $(1.69)$ & 2.77 & $(1.88)$ \\
\hline Assessment Inventory (max. 3) \\
\hline Sensory & 1.87 & $(0.41)$ & 1.92 & $(0.31)$ & 2.19 & $(0.30)$ & 1.41 & $(0.20)$ \\
\hline Cognitive & 1.79 & $(0.36)$ & 1.80 & $(0.31)$ & 2.04 & $(0.35)$ & 1.46 & $(0.15)$ \\
\hline Socio-Emotional & 2.05 & $(0.48)$ & 2.11 & $(0.42)$ & 2.41 & $(0.29)$ & 1.50 & $(0.19)$ \\
\hline Motor & 2.08 & $(0.49)$ & 2.07 & $(0.55)$ & 2.43 & $(0.26)$ & 1.67 & $(0.16)$ \\
\hline
\end{tabular}

Note. SLI = Specific Language Impairment $(\mathrm{N}=84)$

Note. ${ }^{*}=$ Reading Comp. $=$ Reading Comprehension

Note. ${ }^{* *}=$ The overall reading level

In the Assessment Inventory (max. 3p/category, four categories) special education teachers evaluated the children's sensory, cognitive, socio-emotional, and motor development. Surprisingly, there were no significant differences between these four categories (see Table 4).

For further analysis, the participants were divided into three age groups, of which had difficulties (scored below 1.6 of a possible 3.0) with auditory discrimination $(\mathrm{M}=1.38$, 
$\mathrm{SD}=0.44)$ in the category of sensory development and in auditory memory $(\mathrm{M}=1.44, \mathrm{SD}=$ 0.53) from category of cognitive development. Difficulties also occurred with linguistic skills such as semantics $(\mathrm{M}=1.59, \mathrm{SD}=0.53)$ and with dysnomia $(\mathrm{M}=1.43, \mathrm{SD}=0.51)$ in the category of cognitive development.

Surprisingly, the oldest participants performed worse in all overall cognitive development categories (see Table 4).

\subsubsection{Summary of the Results of Study 1}

The results of the Auditory-Visual Matching Test for the children diagnosed with dyslexia $(n=52)$ were very similar to those of earlier studies (Karma, 1989, 2002b; Kujala et al., 2001; Törmänen \& Takala, 2008). The results for the children diagnosed with SLI support the view of auditory deficits (Tallal, 2000). The Assessment Inventory showed no significant differences between the four categories, which supports the view of previous studies (Bishop, 1990; Johnson, 1992) that children with SLI have problems with auditory, visual, tactile, and phonetic perception, as well as with motor tasks. Difficulties in auditory discrimination in the category of sensory development, as well as difficulties in auditory memory and in linguistic skills such as semantics and dysnomia in the category of cognitive development, were expected based on common theories about core deficits in SLI (Tallal, 2000). Surprisingly, the oldest participants performed worse overall in all cognitive development categories, which supports the view of comorbidity in developmental disorders (e.g., Botting \& Conti-Ramsden, 2000)

\section{Study 2}

Encouraged by the interesting results of the first study, nonverbal auditory-visual matching computer training was carried out among the children with language-based learning disorders (N=48). Study 2 applied a pre-test-intervention-post-test design (see Figure 1).

\subsection{Participants in Study 2}

Altogether 48 children (26 girls and 22 boys) diagnosed with language-based learning disorders such as specific language disorder or developmental dyslexia participated in auditory-visual matching training, called Audilex intervention (Chapter 5.2.2). These children differed from those who participated in study 1. Participants had no additional diagnoses and were in mainstream schools; 23 children were in pre-school (from 6 to 7 yrs; $M=80.09$, $S D=3.16$ ) and 25 were at the first-grade (from 7 to 8 yrs; $M=95.28, S D=3.76$ ).

\subsection{Methods in Study 2}

In study 2, the Auditory-Visual Matching Test was used before and after the intervention. In the pre-test, a rigorous practice procedure was applied before the presentation of the experimental tasks to ensure that all children understood the directions for the computer tasks. Special teachers trained to use the Auditory-Visual Matching Games and Test conducted the intervention. An Assessment Inventory was then used after the intervention (see description on page 12).

\subsubsection{Reading skill tests}

Scores from two reading skill tests served as criteria for participation in the intervention. The Standardized Elementary School Reading Test Battery (children at first-grade) showed that 
the overall reading level (max. 9) was below the age-normal range: in reading comprehension $(M=4.46, \quad S D=2.06)$ and in decoding $(M=4.00, S D=1.79)$. The School-Readiness Assessment (Vauras et al., 1994), commonly used in Finnish schools, was used with children at pre-school $(n=23)$. This test measured knowledge of the alphabet among the 19 most frequently appearing letters in the Finnish language, which the special education teacher presented visually one at a time; the children were then asked to name the letter shown. Spelling of the alphabet was measured with 19 letters in the Finnish language, which the experimenter this time presented orally one at a time; the children were then asked to write the requested letter. In addition, a pre-school word recognition measure, consisting of 18 familiar, mainly two-syllable words accompanied by 4 alternative pictures, was administered to assess "pre-reading” skill levels; the maximum score was 39. This measure showed that pre-reading skill levels ( $n=23)$ were below the age-normal range $(M=27.09 ; S D=9.58)$.

\subsubsection{Audilex Intervention in Study 2}

A total of 16 sessions with the computer game took place twice a week over a period of two months, with each training session lasting for about 15 minutes. The teacher or assistant was present at every training session with each pupil in a resource room. This intervention used the pullout system; one pupil left the class to participate in the Audilex session while the others remained. The training sessions were carried out during the school day during regular lessons or breaks, but not when a pupil was in special education.

Both the auditory-visual matching test and games consisted of similar but not identical tasks. The tasks in the games used in the intervention, were also the much more varied. A central feature of the games and the test is that they were completely nonverbal; they attempted to train cognitive operations necessary for learning to read and write successfully, rather than reading and writing themselves. In addition, the computer program aimed to strengthen the student's ability to integrate visual and auditory codes (Karma, 2002b). The aim of the games was to train the participants` perception of sound structures and their skill in combining a visual and an auditory signal. Another aim was to train the participants`sense of direction. The tasks were always read from left to right, which corresponds to moving ahead in time. The games contain no text or semantic meanings, but are aimed at those perceptions and thinking processes, considered preconditions for reading and writing.

Two versions of the game (Karma, 1998) were used during the training period (see Figure 3). In game 1, two patterns appeared on the screen. After a couple of seconds, a sound sequence was played that corresponded to one of the patterns. The player's task was to indicate which of the patterns was played. In game 2, only one pattern was drawn on the screen, followed by a corresponding sound sequence. The player's task was to follow the pattern (from left to right) as it was being played. The player had to press the space bar upon hearing the sound corresponding to the last element of the visual pattern. After a correct response, the participant was rewarded, whereas after an incorrect response, the same pattern was repeated, but the color of the rectangle changed at the moment when the sound corresponding to it was played. 


\section{Macrothink}

Both easy and difficult patterns were randomly presented throughout the training period. Each training session began with a stimulus block with a 1,000-ms stimulus (element) onset asynchrony (SOA) and a 550-ms sound duration. During the sessions, subjects could change the SOA within a window of 200 to $1800 \mathrm{~ms}$, and the sound duration within a window of $30 \%$ to $80 \%$ of the SOA (60-1440 ms). After a couple of training sessions, the pupils would usually change the duration, making it faster or slower, to make the games more difficult. The tempo used in the games had different meanings for different pupils.

\subsection{Results of Study 2}

Statistical analysis were performed using the statistical package SPSS for Windows (version 15.0, SPSS) and were examined with a general linear model repeated-measures ANOVA. The effect size, which measures the magnitude of the treatment effect, was measured with Cohen's $d$ (Cohen, 1988).

Table 5. Descriptive Information of the Training Effect (Repeated Measures ANOVA) in Study 2

\begin{tabular}{|l|l|l|l|l|l|c|l|}
\hline \multicolumn{7}{|c|}{ The Auditory-Visual Matching Test } \\
\hline & \multicolumn{2}{|c|}{ Pre-Test } & \multicolumn{2}{c|}{ Post-Test } & \multicolumn{1}{l|}{} \\
\hline & $M$ & $(S D)$ & $M$ & $(S D)$ & $d$ & $F$ & Sig. \\
\hline LBLD & 18.71 & $(6.80)$ & 24.23 & $(4.52)$ & 0.98 & 33.1 & $<.001$ \\
\hline Pre-School & 17.91 & $(7.15)$ & 23.48 & $(4.63)$ & 0.95 & 19.5 & $<.001$ \\
\hline First-Grade & 19.44 & $(6.50)$ & 24.92 & $(4.40)$ & 1.0 & 14.2 & $<.001$ \\
\hline
\end{tabular}

Note. LBLD = Children with Language-Based Learning Disabilities

Note. Children at pre-school $=$ from 6 to 7 years, and at first-grader_ $=$ from 7 to 8 years

Note. Significant results $(\mathrm{p}<0.05)$ in bold.

Following the audio-visual training period, differences between pre- and post-tests were found in the Auditory-Visual Matching Tests (Table 5). Children diagnosed with language-based learning disorders performed significantly better $[F(1,47)=33.1 ; p<.001$; $d=.98$ ] in the auditory and visual matching test after the training period. Dividing the participants into age groups yielded no differences in the training effect: Children at pre-school performed significantly better $[F(1,22)=19.5 ; p<.001 ; d=.95]$ and as well as did the children at first-grade $[F(1,24)=14.2 ; p<.001 ; d=1.0]$ after the training period. Cronbach's Alpha coefficients were over .68. The training effects appear in Figure 4. 


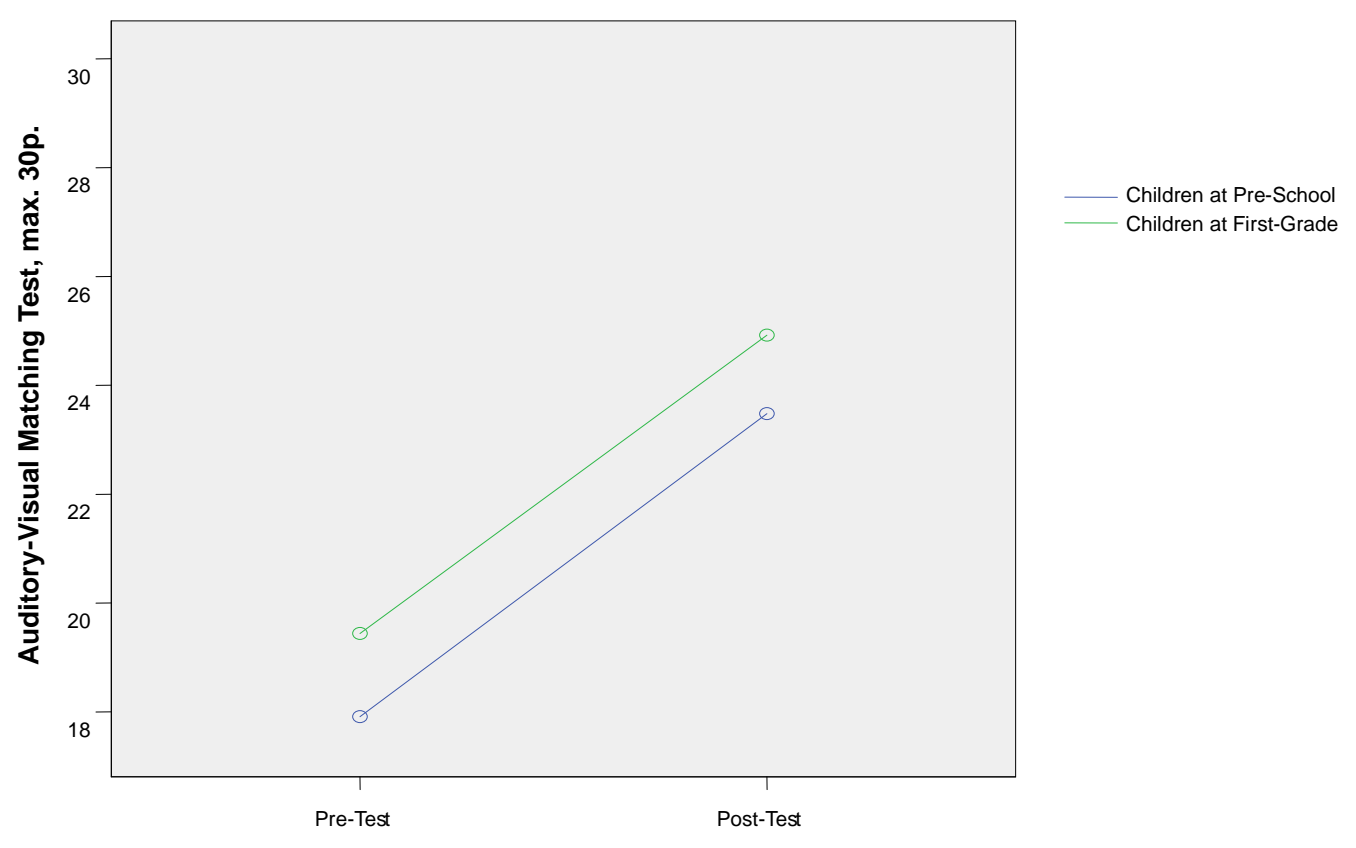

Figure 4. The Training Effect in the Auditory-Visual Matching Intervention in Study 2

After the Audilex training, special education teachers used the Assessment Inventory (max. $3 p /$ category, four categories) to evaluate the children's sensory ( $M=2.55, S D=0.51)$, cognitive $(M=2.46, S D=0.50)$, socio-emotional $(M=2.43, S D=0.50)$, and motor development $(M=2.67$, $S D=0.37)$

\subsubsection{Summary of the Results of Study 2}

This intervention study showed that auditory-visual matching improved after nonverbal computer training in children with language-based learning disorders. According to the Assessment Inventory, after the intervention, children with language-based learning disorders performed well in all four categories of children's development. Thus, the intervention appears to have slightly improved the children's sensory development as well as their overall cognitive performance.

\section{Discussion}

The purpose of this binary study was to investigate auditory-visual matching among children with language-based learning disorders such as SLI or developmental dyslexia. Study 1, which was explorative, showed that children diagnosed with SLI have difficulties in auditory-visual matching similar to those of children with dyslexia.

Despite the wide variety of theories, that attempt to account for SLI, two general approaches have received the most attention. The first posits that SLI arises from deficits in specifically linguistic systems. Such linguistic and sensory deficits are not necessarily exclusive, moreover auditory and visual processing deficits may be linked, as Stein (2001) expressed most elegantly in the form of his magnocellular hypothesis. More importantly, auditory processing theories make explicit claims that phonological deficits arise from auditory 
deficits, which in turn lead to the language disorder. Insofar as literacy requires explicit meta-phonological awareness related to the auditory structure of speech, it is easy to see how an impaired phonological system could lead to dyslexia. For SLI, grammatical difficulties have frequently been tied to imperfect perception of the relevant morphological inflections (Rosen, 2003). Some researchers have hypothesized that limitations in (verbal) working memory arising from a phonological coding deficit can impede the learning of various grammatical structures (Joanisse \& Seidenberg, 1998).

Other investigators (Bailey \& Snowling, 2002) have assumed a common substrate for dyslexia and SLI, suggesting in effect that dyslexia is a mild form of SLI. But this assumption is likely justified only for children whose SLI is characterized by expressive language difficulties and phonological processing problems, rather than for those who exhibit pragmatic language abnormalities involving difficulties with the use of language in interaction. These distinctions between different forms of language difficulty have sometimes been obscured by the use of the term 'language learning impaired', but it is important to note that SLI children have more extensive language problems than do dyslexic children, encompassing poor vocabulary, grammatical deficits and problems with the comprehension and production of sentence structure.

An important result of study 1 was comorbidity in SLI. According to formal diagnoses, $63 \%$ of participants also had additional diagnosis. The Assessment Inventory, which explored different skills and possible deficits in the children's development of overall cognitive performance, also reflected similar results. Presumably, language-based learning disorders are characterized by a broad spectrum of developmental impairments, as many studies have also reported, comorbidity in SLI. According to Tomblin et al. (2000), children with language impairments are at significantly greater risk for both reading disability and behavioral disorders. Children with SLI have been reported to experience concurrent difficulties in the area of social and behavioral development (Botting \& Conti-Ramsden, 2000; Redmond \& Rice, 1998), which many believe arise from such factors as frustration, peer rejection, and lack of confidence in the face of poor linguistic skills. However, there is now increasing concern that problems with social relationships and other behavioral difficulties may be characteristic of children with SLI well after language difficulties have supposedly been resolved (Clegg, Hollis \& Rutter, 1999). This supports the results of this study in which younger participants performed better than did older ones in the assessment of overall performance. Offering individual and qualified education to children with specific language impairments requires comprehensive assessment of their cognitive strengths and difficulties in order to specify more accurately the nature of their difficulties. Assessment should form part of the evaluation and follow-up of children with language-based learning disorders. The Assessment Inventory used in this binary study can served as practical tool to investigate and evaluate children with language-based learning disorders.

Study 2 showed that nonverbal computer training significantly improved auditory-visual matching in children with language-based learning disorders. This result was expected based on earlier studies (e.g., Karma, 1989, 2002b; Kujala et al., 2001), and also supports the view that phonological deficits arise from auditory deficits, which may in turn lead to the 
language-based learning disorder. Focusing the training on a combination of auditory and visual processing revealed significant improvements in reading skills and comprehension (Kujala et al., 2001). Because auditory-visual matching training is nonverbal, explanations can be directed towards perception and processing. The effects of this intervention could also be connected to motivational factors; the engagement between the student and the researcher yields positive interaction and further change in overall cognitive performance.

The results of this binary study cannot be generalized due to the unavoidable limitations of the research design. Study 2 had no delayed test after intervention. In this study reading skill tests served to select participants; in future studies, however, it would be interesting to observe possible effects in reading skill tests as well. Additional research is necessary to determine (a) whether these children would, despite comorbidity, benefit from long-lasting intervention and (b) whether impaired auditory-visual matching is associated with lasting language-related difficulties.

\subsection{Implications for Practice}

Training in auditory-visual matching could be an opportunity for some children at risk for language-based learning disabilities, as well as for older students. Success in training emboldens confidence, which can motivate students to practice, focus and concentrate on reading, which, in turn, could prevent the otherwise cumulative disadvantages of learning disabilities. Despite various intervention programs, studies show accelerating numbers of learning disabilities (Vaughn \& Fuchs, 2003); the need for practical methods for children at risk is evidently growing. Hopefully the intervention used in this study can be easily applied in pre-school or school settings, and the teachers or school-assistants could carry it out. Such a plan would also be cost-effective.

In addition, the auditory-visual matching training could also serve as an opportunity for older students at risk for comorbidity. The ease and playfulness of the auditory-visual matching computer program seems to motivate students, thus encouraging them to practice otherwise difficult tasks. Further, the auditory-visual matching training might have international implications because of the promising results of this study as well as of earlier studies (Kujala et al., 2001; Törmänen \& Takala, 2009), and could be considered a universal instrument due to its nonverbal character.

In conclusion, language development is a dynamic process involving various aspects of social, cognitive and emotional behaviors. To acquire a sound base for linguistic development, a child must become aware of how to use language as a means of communication, learning and transmission of emotions. Children with language-based learning disorders cannot use language and related skills optimally, and meet many obstacles in tapping everyday learning opportunities. Thus preventing cumulative disadvantages and providing interventions that take into account the multidimensional nature of language development is of crucial importance.

\section{Acknowledgement}

The present study benefited from the support of the Finnish Cultural Foundation. I would like 
to thank all those special education teachers who evaluated and trained the children in study 2, especially special education teacher and vice-principal Pia Puupponen, who organized the training in her school.

\section{References}

Ahissar, M., Protopapas, A., Reid, M., \& Merzenich, M.M. (2000). Auditory processing parallels reading abilities in adults. Proceedings of the National Academy of Sciences of the United States of America, 97(12), 6832-6837.

Alexander D.W., \& Frost B.P., (1982). Decelerated synthesized speech as a means of shaping speed of auditory processing of children with delayed language. Percept Motor Skills, 55, 783-792.

Anderson, K.C., Brown, C.P., \& Tallal, P. (1993). Developmental language disorders: Evidence for a basic processing deficit. Current Opinion in Neurology and Neurosurgery, 6(1), 98-106.

Asikainen, M. (2005). Diagnosing specific language impairment. Doctoral Thesis, University of Tampere.

Bailey, P.J., \& Snowling, M.J. (2002). Auditory processing and the development of language and literacy. British Medical Bulletin, 63, 135-146.

Beitchman, J. (1996). Long-term consistency in Speech/Language profiles: II. behavioral, emotional, and social outcomes. Journal of the American Academy of Child Adolescent Psychiatry, 35(6), 815.

Beitchman, J. (2001). Fourteen-year follow-up of Speech/Language-impaired and control children: Psychiatric outcome. Journal of the American Academy of Child Adolescent Psychiatry, 40(1), 75-82.

Benasich, A., \& Tallal, P. (2002). Infant discrimination of rapid auditory cues predicts later language impairment. Behavioural Brain Research, 136(1), 31-49.

Bishop, D.V.M. (1992). The underlying nature of specific language impairment. Journal of Child Psychology and Psychiatry and Allied Disciplines, 33(1), 3.

Bishop, D.V.M. (2002). The role of genes in the etiology of specific language impairment. Journal of Communication Disorders, 35(4), 311-328.

Bishop, D.V.M., \& Adams, C. (1990). A Prospective Study of the Relationship between Specific Language Impairment, Phonological Disorders and Reading Retardation. Journal of Child Psychology and Psychiatry, 31(7), 1027-1050.

Bishop, D.V.M., \& Snowling, M.J. (2004). Developmental dyslexia and specific language impairment: Same or different? Psychological Bulletin, 130(6), 858-886.

Bishop, D.V.M., (2006). Distinct genetic influences on grammar and phonological short-term memory deficits: Evidence from 6-year-old twins. Genes, Brain, and Behavior, 5(2), 
158-169.

Bishop, D.V.M., Adams, C., V., Nation, K., \& Rosen, S. (2005). Perception of transient nonspeech stimuli is normal in specific language impairment: Evidence from glide discrimination. Applied Psycholinguistics, 26(2), 175-194.

Bishop, D.V.M., Carlyon, R.P., Deeks, J.M., \& Bishop, S.J. (1999b). Auditory temporal processing impairment: Neither necessary nor sufficient for causing language impairment in children. Journal of Speech, Language, and Hearing Research, 42, 1295-1310.

Botting, N., \& Conti-Ramsden, G. (2000). Social and behavioural difficulties in children with language impairment, Child Language Teaching \& Therapy, 16, 105-120.

Bruce, B. (2006). ADHD and language impairment. European Child Adolescent Psychiatry, 15(1), 52-60.

Clegg, J., Hollis, C., \& Rutter, M. (1999). Life sentence: What happens to children with developmental language disorders in later life? Bulletin of the Royal College of Speech and Language Therapists, 571, 16-18.

Coady, J.A., Kluender, K.R., \& Evans, J.L. (2005). Categorical perception of speech by children with specific language impairments. Journal of Speech, Language \& Hearing Research, 48(4), 944-959.

Cohen L.S. (1988). Statistical power analysis for the behavioral sciences. Hillsdale, NJ: Erlbaum.

Cohen, N. (2000). The interface between ADHD and language impairment: An examination of language, achievement, and cognitive processing. Journal of Child Psychology and Psychiatry and Allied Disciplines, 41(3), 353.

Corriveau, K., Pasquini, E., \& Goswami U. (2007). Basic auditory processing skills and specific language impairment: A new look at an old hypothesis. Journal of Speech, Language, and Hearing Research, 50, 647-666.

Eden, G.F., Stein, J.F., Wood, H.M., \& Wood, F.B. (1995). Temporal and spatial processing in reading disabled and normal children. Cortex, 31(3), 451-68.

Eden, G.F., VanMeter, J.W., Rumsey, J.M., Maisog, J.M., Woods, R.P., \& Zeffiro, T.A. (1996). Abnormal processing of visual motion in dyslexia revealed by functional brain imaging. Nature, 382(6586), 66-69.

Estrem, T.L. (2005). Relational and physical aggression among preschoolers: The effect of language skills and gender. Early Education \& Development, 16(2), 207-232.

Fujiki, M., Brinton, B., \& Clarke, D. (2002). Emotion regulation in children with specific language impairment. Language, Speech Hearing Services in Schools, 33(2), 102-111.

Gilger, J., \& Kaplan B., J. (2001). Atypical brain development: A conceptual framework for understanding developmental learning disabilities. Developmental Neuropsychology, 20(2), 
465-481.

Glogowska, M., Roulstone, S., Peters, T.J., \& Enderby, P. (2006). Early speech- and language-impaired children: Linguistic, literacy, and social outcomes. Developmental Medicine \& Child Neurology, 48(6), 489-494.

Graham, S., \& Golan, S. (1991). Motivational influences on cognition: Task involvement, ego involvement, and depth of information processing. Journal of Educational Psychology, 83, 187-194.

Hari, R., \& Renvall, H. (2001). Impaired processing of rapid stimulus sequences in dyslexia. Trends in Cognitive Sciences, 5(12), 525-532.

Haynes, C., \& Naidoo, S. (1991). Children with specific speech and language impairment. Oxford: Mac Keith Press.

Helzer, J. (1996). Auditory temporal resolution in specifically language-impaired and age-matched children. Perceptual and Motor Skills, 83(3), 1171-1181.

Hill, E. (2001). Non-specific nature of specific language impairment: A review of the literature with regard to concomitant motor impairments. European Journal of Disorders of Communication, 36(2), 149-171.

International Statistical Classification of Diseases and Related Health Problems,10th Revision, Version for $2007 . \quad$ [Online] Available: http://www.who.int/classifications/apps/icd/icd10online/ (July 2, 2008).

Joanisse, M.F., \& Seidenberg, M.S. (1998). Specific language impairment: A deficit in grammar or processing? Trends in Cognitive Sciences, 2(7), 240-247.

Johnson J.S. (1992). Critical period effects in second language acquisition: The effect of written versus auditory materials on the assessment of grammatical competence. Language Learning, 42, 217-248.

Karma, K. (1984). Musical aptitude as the ability to structure acoustic material International Journal of Music Education, 3.

Karma, K. (1989). Auditive structuring as a basis for reading and writing. In H. Breuer, \& K. Ruoho, (Eds.), Pädagogische-psychologishe Prophylaxe bei 4-8 jährigen kindern. Jyväskylä Studies in Education. Psychology and Social Research, 71.

Karma, K. (1998). Audilex, tietokoneohjelma lukemis- ja kirjoitushäiriöiden diagnosointiin ja kuntouttamiseen [Audilex - the computer program to diagnose and train dyslexia; in Finnish][Online] Available: http://www.compaid.fi/audilex.htm. (June 3, 2008).

Karma, K. (1999). Auditory structuring in explaining dyslexia. Proceedings of the Eight International Workshop on the Cognitive Sciences on Natural Language Processing. Galway: Information Technology Centre, National University of Ireland.

Karma, K. (2002b). Auditory structuring in explaining dyslexia. In P. McKevitt, S. Ó. 


\section{1ll Macrothink}

International Journal of Education

ISSN 1948-5476

2009, Vol. 1, No. 1: E8

Nualláin and Mulvihill, C. (Eds.), Language, vision, and music. Amsterdam: John Benjamin's Publishing Company.

Kujala, T., Karma, K., Ceponiene, R., Belitz, S., Turkkila, P., \& Tervaniemi, M. (2001). Plastic neural changes and reading improvement caused by audiovisual training in reading-impaired children. Proceedings of the National Academy of Sciences of the United States of America, 98(18), 10509-10514.

Leonard, L.B. (1998). Children with specific language impairment. Cambridge, MA, USA: MIT Press.

Lepola, J., Poskiparta, E., Laakkonen, E., \& Niemi, P. (2005). Development of and relationship between phonological and motivational processes and naming speed in predicting word recognition in grade 1. Scientific Studies of Reading, 9(4), 367-388.

Lindeman, J. (1998). Ala-asteen Lukutesti: Tekniset tiedot [Standardized, comprehensive school reading test: Technical report]. Academic Dissertation. Åbo Akademi University Press.

Lindeman, J. (2000). Ala-asteen Lukutesti (ALLU) [Standardized, comprehensive school reading test]. Jyväskylä, Finland: Gummerus.

Locke, J. (1994). Gradual emergence of developmental language disorders. Journal of Speech and Hearing Research, 37(3), 608-616.

McArthur, G.M., \& Bishop, D.V.M. (2001). Auditory perceptual processing in people with reading and oral language impairments: Current issues and recommendations. Dyslexia,7(3), 150-170.

McCabe, P. (2005). Social and behavioral correlates of preschoolers with specific language impairment. Psychology in the Schools, 42(4), 373-387.

Nicolson, R.I., Fawcett, A.J., \& Dean, P. (2001). Developmental dyslexia: The cerebellar deficit hypothesis. Trends in Neurosciences, 24(9), 508-511.

Norrelgen, F.,Lacerda, F., \& Forssberg, H. (2002). Temporal resolution of auditory perception and verbal working memory in 15 children with language impairment. Journal of Learning Disabilities, 35(6), 540-546.

Onatsu-Arvilommi, T., \& Nurmi, J.E. (2000). The role of task-avoidant and task-focused behaviors in the development of reading and mathematical skills during the first school year: A cross-lagged longitudinal study. Journal of Educational Psychology, 92(3), 478-491

Poskiparta, E., Niemi, P., Lepola, J., Ahtola, A., \& Laine, P. (2003). Motivational-emotional vulnerability and difficulties in learning to read and spell. The British Journal of Educational Psychology, 73(2), 187-206.

Powell, R.P., \& Bishop, D.V.M. (1992). Clumsiness and perceptual problems in children with specific language impairment. Developmental Medicine and Child Neurology, 34, 755-765. 
Ramus, F. (2003). Developmental dyslexia: Specific phonological deficit or general sensorimotor dysfunction? Current Opinion in Neurobiology, 13(2), 212-218.

Redmond, S.M., \& Rice, M.L. (1998). The socioemotional behaviors of children with SLI: Social adaptation or social deviance? Journal of Speech, Language, and Hearing Research, 41, 688-700.

Richardson, U. Thomson, J.M., Scott, S.K., \& Goswami, U. (2004). Phonological representation in dyslexic children. Dyslexia, 10(3), 215-233.

Rosen, S. (2003). Auditory processing in dyslexia and specific language impairment: Is there a deficit? What is its nature? Does it explain anything? Journal of Phonetics, 31(3-4), 509-527.

Rowe, K., \& Rowe (1999). Investigating the relationship between students' attentive-inattentive behaviors in the classroom and their literacy progress chapter 6 epistemological and methodological issues: A synthesis. International Journal of Educational Research, 31(1-2), 81.

Snowling, M. (1998). Dyslexia as a phonological deficit: Evidence and implications. Child and Adolescent Mental Health, 3(1), 4-11.

Snowling, M.J. (2001). From language to reading and dyslexia.. Dyslexia, 7(1), 37-46.

Spitz, R., Tallal, P., Flax, J., \& Benasich A. (1997). Look who's talking. A prospective study of familial transmission of language impairments. Journal of Speech, Language, and Hearing Research, 40(5), 990-1001.

Stein, J. (2001). The magnocellular theory of developmental dyslexia. Dyslexia, 7(1), 12-36.

Stein, J.F., \& Walsh, V. (1997). To see but not to read; the magnocellular theory of dyslexia. Trends in Neuroscience, 20, 147-152.

Tallal P., Miller S., \& Fitch R. (1993). Neurobiological basis of speech: A case for the preeminence of temporal processing. Annals of the New York Academy of Sciences, 682, 27-47.

Tallal, P. (2000). Experimental studies of language learning impairments: From research to remediation. In D. Bishop \& L. Leonard (Eds.), Speech and language impairments in children .Hove: Psychology Press. pp. 131-155

Tallal, P., \& Piercy, M. (1973). Defects of non-verbal auditory perception in children with developmental aphasia. Nature, 241, 468 - 469.

Tallal, P., \& Piercy, M. (1974). Developmental aphasia: Rate of auditory processing and selective impairment of consonant perception. Neuropsychologia, 12, 83-93.

Temple, E., Poldrack, R. A., Protopapas, A., Nagarajan, S., Salz, T., \& Tallal, P. (2000). Disruption of the neural response to rapid acoustic stimuli in dyslexia: Evidence from functional MRI. Proceedings of the National Academy of Sciences of the United States of 
America, 97(25), 13907-13912.

Tomblin, J.B., Records, N.L., Buckwalter, P., Xuyang Z., Smith, E., \& O'Brien, M. (1997). Prevalence of specific language impairment in kindergarten children. Journal of Speech, Language \& Hearing Research, 40(6), 1245-1260.

Tomblin, J.B., Zhang, X., \& Buckwalter, P. (2000). The association of reading disability, behavioral disorders, and language impairment among second-grade Children. Journal of Child Psychology \& Psychiatry \& Allied Disciplines, 41(4), 473-483.

Toppelberg, C., \& Shapiro, T. (2000). Language disorders: A 10-year research update review. Journal of the American Academy of Child Adolescent Psychiatry, 39(2), 143-152.

Törmänen, M. \& Takala, M. (2009). Auditory processing in developmental dyslexia: An exploratory study of an auditory and visual matching training program with Swedish children with developmental dyslexia. Scandinavian Journal of Psychology, 50, 277-285.

Törmänen, M.R.K., Takala, M., \& Sajaniemi, N. (2008). Learning disabilities and the auditory and visual matching computer program. Support for Learning, 23(2), 80-88.

van der Lely, H.K.J. (1998). SLI in children: Movement, economy, and deficits in the computational-syntactic system. Language Acquisition, 7(2-4), 161-193.

van der Lely, H.K.J., \& Stollwerck, L. (1997). Binding theory and grammatical specific language impairment in children. Cognition, 62(3), 245-290.

Vaughn, S., \& Fuchs, L.S. (2003). Redefining learning disabilities as inadequate response to instruction: The promise and potential problems. Learning disabilities research and practice. Learning Disabilities Research and Practice, 18, 137- 146.

Vauras, M., Poskiparta, E., \& Niemi, P. (1994). Kognitiivisten taitojen ja motivaation arviointi koulutulokkailla ja 1. luokan oppilailla. [Evaluation of cognitive skills and motivation in pre-school children and children in $1^{\text {st }}$ grade], University of Turku, Finland. Oppimistutkimuksen keskus, [Centre of Learning Research].

Vauras, M., Rauhanummi, T., Kinnunen, R., \& Lepola, J. (1999). Motivational vulnerability as a challenge for educational interventions. International Journal of Educational Research, 31, 515-531.

Webster, R.I., Erdos, C., Evans, K., Majnemer, A., Eva Kehayia, PhDe, Thordardottir, E., Evans, A., \& Shevell, M. I. (2006). The Clinical Spectrum of developmental language impairment in school-aged children: Language, cognitive, and motor findings. Pediatrics, 118(5), 1541-1549.

Westby, C., \& Blalock, E. (2005). Assessment of social-emotional status in children with language impairments. Seminars in Speech and Language, 26(3), 160-169.

\section{Appendix}

Appendix 1. Assessment Inventory: Children’s Overall Cognitive Development (max. 3p.) 
I Sensory development:

1. Auditory discrimination

2. Visual discrimination

3. Tactile discrimination

4. Combining sensory and motor functions

II Cognitive development

5. Linguistic skills

5a. Articulation

5b. Semantics

5c. Grammatical development (syntacs and morphology)

5d. Dysnomia

6. Memory skills

6a. Visual memory

6b. Auditory memory

7. Cognitive thinking

7a. Categorization and observation skills

7b. Logical argumentation

7c. Problem solving skills

8. Reading and writing skills (over 8 yrs)

9. Mathematical skills

9a. Mathematical vs. linguistic skills

9b. Understanding spatial concepts

III Social-Emotional development

10. Independent initiative

10a. Independence

10b. Responsible

10c. Ability to start and finish tasks

11. Interactions skills

11a. Being a member of a group 
11b. Pay attention to others

11c. Own opinions

12. Ability to concentrate

12a. In group

12b. Alone

IV Motor development

13. Knowledge of own body

13a. Pointing

13b. Naming

13c. Awareness

14. Gross Motor Skills

15. Fine Motor Skills

16. Spatial and temporal skills

16a. Orientation

16b. Motor possession of spatial concepts

16c. To orient oneself in a time concept 